\title{
Didáctica de la ética. El aporte de Mockus a la gobernabilidad en Colombia
}

\author{
José Ignacio Bolaños Motta* \\ María Teresa Castellanos Sánchez \\ Javier Orlando Rojas Gómez ${ }^{* * *}$
}

Recibido: 12 de noviembre del 2018

Evaluado: 7 de febrero de 2019

Aceptado: 25 de febrero del 2019

Citar como: Bolaños Motta, J. I., Castellanos Sánchez, M. T. y Rojas Gómez, J. O. (2019). Didáctica de la ética. El aporte de Mockus a la gobernabilidad en Colombia. Hallazgos, 16(32), 151-167. DOI: https://doi. org/10.15332/2422409X.4817

\section{ReSUMEN}

Este texto retoma propuestas de Antanas Mockus durante sus dos programas de gobierno en la Alcaldía de Bogotá, teniendo por objetivo resignificar a nivel histórico momentos claves de la gobernabilidad mockusiana, vista como estrategia didáctica viable aún actualmente, y aplicable para los habitantes de las diversas urbes del país. La reflexión abarca un análisis crítico de las estrategias de gobierno desarrolladas en Bogotá, que pretendieron fortalecer dos valores básicos de la sociedad: a) la vida $y, b$ ) el respeto. Como conclusión, se indica el aporte del programa de gobierno de Mockus a la gobernabilidad en el país, que dio un lugar a la pedagogía en la política colombiana pues generó un modelo didáctico para el fortalecimiento de la ética ciudadana, lo cual hace posibles nuevos ciudadanos, y es concebido como gran aporte al ejercicio de la política nacional.

Palabras clave: ciudad, ética, gobernabilidad, pedagogía, política.

Licenciado en Música y magíster en Educación Multicultural y Etnoeducación de la Universidad del Cauca, Popayán, Colombia. Docente investigador universitario, coordinador del grupo Almunedar (Alma, Mundo, Educación y Arte) grupo adscrito a la Facultad de Ciencias Humanas y de la Educación de la Universidad de los Llanos, Sede Villavicencio, Meta, Colombia. Correo electrónico: jbolanos@unillanos.edu.co - ORCID: https://orcid. org/0000-0002-9976-1808

** Doctora en Ciencias - Educación Matemática. Docente de la Universidad de los Llanos, Sede Villavicencio, Meta, Colombia. Correo electrónico: mcastellanos@unillanos.edu.co

*** Estudiante asistente de investigación del grupo Almunedar (Alma, Mundo, Educación y Arte) grupo adscrito a la Facultad de Ciencias Humanas y de la Educación. Universidad de los Llanos, Sede Villavicencio, Meta, Colombia. Correo electrónico: javier.rojas.gomez@unillanos.edu.co - ORCID: https://orcid.org/0000-0003-1522-9273 


\title{
Didactics of ethics. The contribution of Mockus to governance in Colombia
}

\begin{abstract}
This text takes up proposals from Antanas Mockus during his two government programs in the Mayor's Office of Bogotá, with the objective of resignifying at a historical level key moments of Mockusian governance, seen as a didactic strategy that is still viable, and applicable to the inhabitants of different cities from the country. The reflection includes a critical analysis of the government strategies developed in Bogotá, which aimed to strengthen two basic values of society: a) life and b) respect. In conclusion, the contribution of Mockus' government program to governance in the country is indicated, which gave a place to pedagogy in Colombian politics because it generated a didactic model for the strengthening of citizen ethics, making possible new citizens, and is conceived as a great contribution to the exercise of national politics.
\end{abstract} Received: november 12, 2018 Evaluated: february 7, 2019 Accepted: february 25, 2019

Keywords: City, ethics, governance, pedagogy, politics. 


\section{Didática da ética. A contribuição do Mockus à governabilidade na Colômbia}

Recebido em 12 de novembro de 2018 Avaliado: 7 de fevereiro de 2019 Aceito: 25 de fevereiro de 2019

\section{Resumo}

Este texto retoma propostas do Antanas Mockus durante seus dois planos de governo na Prefeitura de Bogotá, tendo com objetivo resignificar no âmbito histórico momentos chave da governabilidade mockusiana, vista como estratégia didática viável ainda atualmente, e aplicável para os habitantes das diversas urbes do país. A reflexão abrange uma análise crítica das estratégias de governo desenvolvidas em Bogotá, que pretenderam fortalecer dois valores básicos da sociedade a) a vida e b) o respeito. Como conclusão indica-se o aporte do programa do governo do Mockus à governabilidade no país, que deu lugar pedagogia na política colombiana porque gerou um modelo didático para o fortalecimento da ética cidadã, o qual faz possíveis novos cidadãos e é concebido como uma grande contribuição ao exercício da política nacional.

Palavras-chave: cidade, ética, governabilidade, pedagogia, política. 
"Detrás de las acciones van los corazones". Extracto del Sefer HaJinuj - Libro de Educación (original escrito en idioma hebreo)-, Texto anónimo del siglo XIII

\section{INTRODUCCIÓN}

Hacia principios de los años noventa aparece en la esfera política colombiana, un personaje atípico a la gobernabilidad del país; se trata de una figura pública integrada por tres elementos no tan fácilmente agrupables en un actor político. Se hace referencia a: a) el intelectual; b) el maestro y, c) el político. Aurelijus Rutenis Antanas Mockus Sivickas conocido ampliamente en Colombia y el extranjero como Antanas Mockus, quien había ejercido el cargo de rector de la Universidad Nacional de Colombia, pasa a ocupar en dos ocasiones -no consecutivas-, la Alcaldía Mayor de la ciudad de Bogotá: una a finales del siglo XX (1995-1998) y otra a comienzos del siglo XXI (2001-2003). Es de notar que durante este período se dio lugar a "la implementación del modelo neoliberal en Colombia" (Cruz, 2010, p. 274) con motivo de la apertura económica propiciada -durante y con posterioridad- al Gobierno de Cesar Gaviria Trujillo. Mockus se destaca dentro del común de actores políticos colombianos por valiosas cualidades que él mismo ha sabido explotar como son la innovación, la irreverencia y la honestidad, entre otras. Es así como dicho actor político -en determinado momento de la historia y ocupando uno de los cargos políticos más importantes para la política colombiana: la Alcaldía Mayor de la ciudad de Bogotá-, desarrolló desde su programa de gobierno en la Alcaldía, la reinvención sobre el espacio común y las reglas establecidas sobre lo común (Laval y Dardot, 2013), repensando el asunto de la ciudadanía, más allá del sentido de lo público o de lo privado.

Durante sus mandatos se generaron un cúmulo de acciones que dejaron huella en la memoria de los capitalinos, y es precisamente por ello que se apela a la necesidad de analizar dichas prácticas políticas -que se asumen de coherencia ética-, pues resulta desafortunado que en Colombia, muchas veces es precisamente: "el Estado el que mina los mecanismos de la moralidad individual" (Laval y Dardot, 2013, p. 430). Durante las administraciones de Mockus se aplicaron un conjunto de prácticas comunes en las que todos los ciudadanos -o la mayoría de ellos- lograban reconocerse, dada la claridad ética y moral de la propuesta política, aciertos que dieron lugar a múltiples opiniones y que serán expuestos posteriormente de forma más amplia. El presente texto surge como un ejercicio de reflexión histórico-crítica sobre un grupo de hechos pedagógicos y también políticos desarrollados en la capital de Colombia, dados los "incuestionables éxitos en el mejoramiento de las percepciones, actitudes, conocimientos y comportamientos de los habitantes de la ciudad" (Sáenz, 2009, p. 26) de Bogotá. Los hechos o acciones políticas generadas por las administraciones de Mockus posibilitaron una re-significación de estas, sopesando los aportes en torno a la gobernabilidad en Colombia, su relación posible con la pedagogía, la didáctica (Camilloni, 2007) y su implicación con la enseñabilidad de una ética ciudadana. A lo largo de las administraciones mencionadas, "la política está guiada por un bien común [y que por consiguiente] 
debe estar sometida a fines morales colectivos" (Laval y Dardot, p. 2015, 71) dado que lo buscado es un objetivo político social común. El presente tema se justifica en tanto que resulta necesario retomar la discusión sobre el cuestionamiento en torno a lo culturalmente correcto (lo moral), y también lo universalmente ético para múltiples contextos identificando de igual manera lo universal (Montoya y Cendrós, 2007), como una política sobre lo común.

En la actualidad, Colombia afronta una crisis quizás nunca vista: sus instituciones están permeadas de una corrupción naturalizada y con ello, aumenta el riesgo en la estabilidad del sistema democrático colombiano. Sobre el tema de lo moral o lo éticamente correcto en el sistema democrático, Antanas Mockus y su equipo lograron desarrollar un conjunto de políticas que a nivel institucional -desde la Alcaldía Mayor de Bogotá-, pretendieron generar nuevas construcciones de ciudadanía, estableciendo un grupo de acuerdos sobre lo común, ello a través de un concreto conjunto de acciones políticas con una posición ética en favor del respeto de la vida ${ }^{1}$, y de atención directa a diversas formas de conflictividad social. El trabajo pedagógico-político, desarrollado en la capital colombiana, se asume en términos del presente escrito como un tema de vital reflexión para la formación de la ciudadanía, considerándolo un asunto

1 En el año 2018 el electo senador Antanas Mockus obtuvo gran protagonismo en el panorama político colombiano; esto se debió a dos razones. La primera es que el político tomó deliberadamente -durante una de las plenarias del Senado de la República-, la decisión de bajarse los pantalones "en frente de sus colegas para pedir silencio" (El Tiempo, 2018). Y de otro lado, por que hizo parte del equipo que gestionó la denominada consulta anticorrupción en donde 11.6 millones de colombianos salieron a las urnas a votar, como "un mensaje político muy fuerte: el renacer de un movimiento ciudadano hastiado de la corrupción". (Redacción El Espectador, 2018). de suma importancia que debe ser sopesado no solo por la sociedad capitalina sino también por la nación, y más aún con posterioridad a los alcances logrados con los recientes acuerdos de La Habana.

\section{El CONTEXTO Y LAS PRÁCTICAS}

A nivel histórico y dando grandes saltos, se dice que existía un modelo de la interacción muy respetuosa entre los ciudadanos de la Bogotá anterior a $1948^{2}$, lo cual tuvo múltiples transformaciones con posterioridad al Bogotazo en tanto el arribo de múltiples nuevos habitantes que llegaron a la capital a lo largo del siglo XX. La sociedad bogotana de finales de ese siglo se vio ampliamente conformada por poblaciones diversas, entre las que se encontraban personas naturales migrantes de diversas regiones, como también desplazados del conflicto armado (Naranjo, 2002) provenientes de diversos lugares de Colombia. Es así como buena parte de la población de la época era considerada como anfibios culturales, término que designa: "la coexistencia de diversas tradiciones y la correspondiente interacción entre diversos conglomerados de creencias e interpretaciones que genera dilemas en materia de identidad cultural" (Mockus, 1994, p. 125). De tal suerte, tanto migrantes como nativos de Bogotá se vieron ante diversas formas de conflictividad social, que aluden a problemas relacionados con el tránsito, la delincuencia común y la violencia en las calles, entre muchos otros problemas; de lo anterior se observa cómo: "la población en

2 En parafraseo, Mockus asegura que en la Bogotá anterior al 9 de abril 1948 (el Bogotazo), el trato de la gente era cortés, respetuoso y jerarquizado. Con posterioridad a 1995, se fortaleció el respeto al otro, pero sin apelación a la desigualdad o a las jerarquías. (Mockus citado por Pardo, 2007). 
general entra en una fase de deterioro profundo de su relación con la ciudad" (Pardo, 2007, p. 146). Es así como para este momento de la historia, la ciudadanía bogotana se encontraba ante problemas como el consumo de alcohol, el uso inadecuado de la pólvora, un tránsito caótico y, agregado a lo anterior, altos índices de violencia ciudadana en las calles. Es de tener en cuenta que para este lapso de tiempo Colombia se hallaba bajo las consecuencias de una apertura económica en donde se había dado vía libre al neoliberalismo, ante lo cual se buscaba también desarrollar un nuevo modelo de país y de ciudadanía:

El neoliberalismo no es solo destructor de reglas, de instituciones, de derechos, es también productor de cierto tipo de relaciones sociales, de ciertas maneras de vivir, de ciertas subjetividades. Dicho de otro modo, con el neoliberalismo lo que está en juego es, nada más y nada menos, la forma de nuestra existencia, o sea, el modo en que nos vemos llevados a comportarnos, a relacionarnos con los demás y con nosotros mismos. (Laval y Dardot, 2013, p. 5).

Dada esta situación, durante la alcaldía de Mockus se generó un grupo de prácticas de control sobre las conductas ciudadanas; dichas prácticas lograron constituirse como experiencias concretas y experimentaciones colectivas sobre lo común. Estas prácticas desarrollaron acciones directas en los colectivos humanos y estuvieron dirigidas a desarrollar una nueva moral al interior de los ciudadanos -y con un sentido predefinido-; las prácticas estaban direccionadas a fortalecer tanto el respeto como la protección de la vida humana, de lo cual podría decirse que pretendía convencer a los sabios y obligar a los necios, a cumplir unas reglas en beneficio de la mayoría. En este mismo sentido se pretendería multiplicar las prácticas $\mathrm{u}$ hombres sabios, en beneficio del común de la ciudadanía. Se generó entonces, al interior de la administración capitalina, un:

Conjunto de los discursos, de las prácticas, de los dispositivos que determinan un nuevo modo de gobierno de los hombres... En segundo lugar, la asignación a la acción política de un objeto completamente específico, o sea, la "sociedad" entendida hasta su trama más fina y, en consecuencia, el individuo como sede del gobierno de sí y punto de apoyo del gobierno de las conductas. (Laval y Dardot, 2013, pp. 16-28).

Para argumentar el tema de análisis propuesto en el presente texto, Bauman (2013) nos dice:

La única manera en que la libertad individual podría tener consecuencias moralmente positivas es -en la práctica, si bien no en la teoría- la responsabilidad de seguir o romper las reglas éticas y legales avaladas por la sociedad. Es posible confiar en los sabios el bien de manera autónoma... pero no es posible que todas las personas sean sabias. (Pp. 37- 38).

Antecedentes a este fenómeno ya había; propuestas similares se implementaron en contextos europeos y, en lo que al contexto colombiano se refiere, existía de forma pretérita la propuesta de Rodrigo Guerrero, alcalde de la ciudad de Cali (Pardo, 2007); no obstante, las prácticas realizadas en la 
ciudad de Bogotá fueron las que más difusión tuvieron, quizás por el hecho de realizarse en los espacios públicos de la capital del país. Las prácticas de puesta en común para la sociedad capitalina se concibieron con nombres o rótulos propios que tenían un sentido didáctico para la formación de la ciudadanía, entre ellas: la ley zanahoria, decreto de control de pólvora, la vacuna contra la violencia, las tarjetas ciudadanas y los mimos; estas se explicarán por separado a continuación ${ }^{3}$.

1. La ley zanahoria: en Colombia la palabra zanahoria (Pardo, 2007; Parra, 2013) hace referencia a todo aquello que es bueno para la salud, sano o saludable, aunque en este caso está muy relacionado con el exceso de alcohol. El propósito de la ley consistía en la regulación de la venta de licor por parte de los expendios de bebidas alcohólicas, los cuales debían cerrar antes de la 1:00 a. m. (aunque la hora podía variar).

2. Decreto de control de pólvora: la prohibición de la pólvora (Redacción El Tiempo, 1995) pretendía evitar la muerte o las lesiones en los niños capitalinos; la consigna al respecto era "ver y no tocar"; el sentido educativo mostraba que la pólvora debería ser manejada por "expertos del oficio" y no por ciudadanos inexpertos $\mathrm{y}$, mucho menos, por menores de edad.

3. La vacuna contra la violencia (o contra la rabia): la acción consistía en gotas administradas por vía oral para que -a

3 Los autores son conscientes del hecho de que existen varias bibliografías (incluso del mismo autor) que abordan la propuesta de Mockus de forma muy amplia y completa; no obstante, se exponen las respectivas prácticas para posteriormente llevar estas actividades a otro plano de reflexión didáctico-pedagógica. nivel simbólico-, la persona asumiera implícitamente autorregulación por sus comportamientos violentos (Tibaná, 1996; Cortina y Martínez, 2001), pues ahora se encontraba desde luego vacunada para esta clase de mal social (Mockus, 2000), problema muy presente al interior de las familias capitalinas.

4. Tarjetas ciudadanas: un grupo de tarjetas eran distribuidas entre los ciudadanos: de un lado había tarjetas rojas que apuntaban con el dedo pulgar hacia abajo (desaprobación), y del otro lado las tarjetas eran blancas y apuntaban con el dedo hacia arriba (aprobación). El uso de estas tarjetas (Mockus, 2001) motivó a los ciudadanos para evaluar comportamientos mal, o bien hechos y capacidad para responder positivamente. Esta actividad estaba dirigida en gran medida a las faltas en el tránsito.

5. Los mimos: se trataba de un grupo de personas contratadas por la alcaldía municipal (vestidas como mimos) que se encargaban de generar una reprensión social a quienes actuaran contra las leyes de tránsito (Mockus, 2000; Díaz, 2009). Con posterioridad, si el ciudadano no atendía a la represión social, entonces intervenía la policía con multas a los infractores.

Las acciones enunciadas -al igual que muchas otras estrategias-, se encargaron de fortalecer el sentido por "lo sano, lo no violento, lo no corrupto [para así paulatinamente] reconocer y mejorar la regulación cultural de la interacción entre desconocidos" (Mockus, 2002a, p. 24). Las actividades dieron resultados muy positivos en lo referente a la disminución de la violencia 
en la ciudad (Beltrán, 2003); se fortalecieron diversas formas de respeto, tales como: el respeto a la vida, el respeto a la salud del otro, y el respeto por el espacio público, entre otras, ideas que ganaron mucho peso en la sociedad (Sáenz, 2009; Pardo, 2007). Con posterioridad a los mandatos de Mockus, se generaron prácticas más equilibradas y se fortalecieron muchos de los valores mencionados, de tal suerte que, al interior de la cultura política y ciudadana de la ciudad de Bogotá, se logró reconocer:

La necesidad de transformar la interacción entre ciudadanos en dirección a una comunicación apreciativa que reconozca los avances y logros de la ciudadanía y la ciudad; una comunicación no violenta donde sea posible que las personas comuniquen sus sentimientos y necesidades. (Mockus, 2003, p. 106).

En consecuencia, se asume que "el lenguaje en la acción es un mediador para el acuerdo" (Gómez y Peñalosa 2014, p. 22). Esto se entiende en tanto que acción y lenguaje son dos elementos que se complementan y se justifican mutuamente, a lo cual se agrega que:

Convivir es llegar a vivir juntos entre distintos sin los riesgos de la violencia, con la expectativa de aprovechar fértilmente nuestras diferencias. El reto de la convivencia es básicamente el reto de la tolerancia a la diversidad y esta encuentra su manifestación más clara en la ausencia de violencia. (Mockus, 2002a, p. 20).

No obstante, la propuesta de Mockus tenía una pretensión formativa que iba más allá de la mera "corrección" de un grupo de conductas ciudadanas; la gobernabilidad de la ciudad estaba direccionada a armonizar tres conceptos claves: a) la ley,; b) la moral y, c) la cultura, partiendo de la previa existencia de un divorcio entre los tres campos, y en la búsqueda de "intentar acercar la cultura a la ley y a la moral" (Mockus, 2000) para así "legitimar la acción de las autoridades dirigidas a garantizar el cumplimento de las normas" (Pardo, 2007, p. 174), pues el divorcio entre los tres aspectos mencionados conduce a una "falta de congruencia que se expresa como violencia, como delincuencia, como corrupción, como ilegitimidad de las instituciones [hecho que se revierte en una] crisis o debilidad de la moral individual" (Mockus, 2002a, p. 68).

De lo anterior, es necesario decir que la unión de los tres factores mencionados estaba direccionada a generar una evolución social en la ciudadanía de la capital de Colombia. Ahora, si bien es cierto que "lo ideal sería, finalmente, que el carácter de las leyes permitiera a los hombres prescindir de todo gobierno" (Laval y Dardot, 2013. p, 26), es muy posible que a la sociedad colombiana le falte mucho para un ideal como este. Por tanto y mientras la ley pasa a ser parte de la cotidianidad del ciudadano sin la vigilancia estricta del Gobierno, se atiende a la necesidad de la autoridad. Antanas Mockus es -a nivel filosófico-, un seguidor de la escuela de Habermas, hecho que se nota en buena parte de sus escritos ${ }^{4}$. De lo anterior se precisa que la teoría habermasiana es desde luego un valioso aporte al campo de la educación (Gómez y Peñaloza, 2014); es así como las propuestas del mencionado exalcalde hallaban una relación con Habermas ante el siguiente hecho:

4 Ver: Mockus (1994, 2000, 2001, 200a y 2003). 
La aplicación de reglas requiere de una prudencia práctica que ha de venir en auxilio de esa razón práctica interpretada en términos de ética del discurso... es menester un sistema de controles internos del comportamiento, capaz de responder positivamente a juicios morales dirigidos por principios, es decir, a convicciones racionalmente motivadoras, y que posibilite la autorregulación del comportamiento. (Habermas, 1998, pp. 86-88).

Es así como se origina un grupo de prácticas a desarrollar, en la búsqueda de posicionar nuevas conductas ciudadanas bajo la convicción motivadora de que se está actuando cívicamente y a favor de la ciudad. Si bien se asume que, al ser una ley justa, esta se ubica por encima del discernimiento moral individual de uno $u$ otro ciudadano, generándose así un "reino de la ley" (Laval y Dardot, 2013, p. 173). Aunque se observa el factor autoridad, se asume que la ley es en sí necesaria para la existencia misma de la sociedad:

Una ley es una regla general de las relaciones entre individuos privados, solo expresa las relaciones generales de los hombres entre sí. No es ni la emanación de un poder trascendente ni la propiedad natural del individuo. Es un modo de organización de los derechos y deberes recíprocos de los individuos unos con otros, objeto de cambios continuos en función de la evolución social. (Laval y Dardot, 2013, p. 130).

Ello implica de muchas formas:

"Poner la ley por encima del hombre". Solo hay un modo de conseguirlo, que es "sustituir al hombre por la ley". El ideal sería, por lo tanto, que las leyes políticas adquirieran la misma inflexibilidad y la misma inmutabilidad que las leyes de la naturaleza, de tal manera que a los hombres les resultara imposible desobedecerlas. (Laval y Dardot, 2013, p. 775).

La aplicación de la ley indica un ejercicio de reflexión por parte del ciudadano, quien reflexiona en torno a las ventajas que la ley le ofrece en tanto que se cuestiona "respecto a su estatus de ciudadano... ¿cuáles son mis responsabilidades?" (Gardner, 2011, p. 106). $\mathrm{Al}$ respecto, es necesario decir que la toma de consciencia sobre los deberes no nace de sí mismo, sino de un aprendizaje reflexivo sobre las condiciones que se desarrollan sobre lo nuestro. Todo lo anterior se genera a través de un distanciamiento y concientización de su propio comportamiento, mediatizado por el proceso de aprendizaje de la regla. Retomando lo expuesto en páginas anteriores, armonizar ley, moral y cultura implica un despliegue de la didáctica, formulando de esta manera la posible implicación de la pedagogía en la formación ciudadanía, aspecto que se desarrollará en el apartado siguiente.

\section{DidÁCTICA DE LA ÉTICA CIUDADANA}

El concepto de ética ha sido cultivo de múltiples discusiones a nivel epistemológico a lo largo de la historia; pensadores de gran peso histórico como Spinoza (2005), Leibniz (Ackerley, 2008), Kant (López, 2008; Montoya y Cendrós, 2007), y Cortina (2000; 2004) -entre muchos otros-, han hecho significativos aportes al desarrollo de la idea de la ética. 
Ante tal multitud de definiciones, se acude a la concepción de ética expuesta por Cortina y Martínez (2001), quienes explican que: "llamamos 'ética' a esa disciplina filosófica que constituye una reflexión de segundo orden sobre los problemas morales" (2001, p. 22). Si bien sobre lo anterior se podría caer en decir que la política de Antanas Mockus implicó el desarrollo de una nueva moral, con valores: quizás nuevos, quizás mejores, debería indicarse un nuevo porvenir de la moral, entendiéndose por esta:

Un conjunto de principios, preceptos, mandatos, prohibiciones, permisos, patrones de conducta, valores e ideales de vida buena que en su conjunto conforman un sistema más o menos coherente, propio de un colectivo humano concreto en una determinada época histórica... La moral es un sistema de contenidos que refleja una determinada forma de vida. (Cortina y Martínez, 2001, p. 14).

La moral es "un concepto de ámbito vecinal" (Gardner, 2011, p. 104), en el cual se hallan puesto de manifiesto los intereses de la comunidad que se encuentra en una relación mutuamente educativa, por lo cual la moral entra a ser parte de un dominio de la comunidad local. Sobre lo anterior, se amplía un poco el problema al decir Bauman que:

"Cualquier moralidad es una costumbre local $-\mathrm{y}$ temporal-, que lo que es moral es un lugar y un momento dados seguramente serán despreciado en otro" (de lo cual se podría también decir que) "las sociedades modernas practican un parroquialismo moral bajo la máscara de promover la ética universal". (Bauman, 2013, pp. 19-21).
No obstante, la moral es un concepto que suele aplicarse más al campo de la subjetividad o de los colectivos humanos -o parroquialismos-, de lo cual se diría que la política de Mockus no da cuenta de una formación moralista para la ciudad. Se pretendió más bien generar un acercamiento a las concepciones sobre lo correcto en el espacio denominado ciudad, y ello por encima de las múltiples concepciones morales de los diversos ciudadanos que habitan el sector, denominándose este fenómeno, como un asunto de ética ciudadana ${ }^{5}$. Por ello, la propuesta de Mockus no pretendía consolidarse como una "nueva moral". Lo anterior adquiere una directa relación en lo que respecta a la responsabilidad que posee el Estado como regulador de lo ético, lo público y de las buenas costumbres de los comunes. Así:

El Estado no puede conformarse ya con asegurar la protección social. Debe asumir un papel más amplio, pero también más flexible, en donde se hace las veces de regulador, contribuyendo a crear una esfera pública eficaz encaminada a generar bienes públicos satisfactorios. (Giddens citado por Laval y Dardot, 2015, p. 450).

De lo anterior, se infiere que el Estado colombiano -a partir de sus nuevas políticas generadas en la Constitución de 1991-, "es productor de cierto tipo de relaciones sociales, de ciertas maneras de vivir, de ciertas subjetividades... la forma de nuestra existencia" (Laval y Dardot, 2013, p. 9). Por su parte, los bienes encaminados a la satisfacción pública son justificables para cualquier contexto, o

\footnotetext{
5 Para los autores es claro que no es esta la terminología usada por el señor Antanas Mockus; es precisamente de ello que se trata la re-significación elaborada a lo largo del presente texto reflexivo.
} 
por lo menos para una amplia mayoría; ello deja ver la posibilidad de una ética. Dicha ética ciudadana, generaría una corregulación de las conductas sociales de los capitalinos, dado que una "conducta es tanto la que se tiene hacia uno mismo como la que se tiene hacia los demás" (Laval y Dardot, 2013, p, 247). Mockus era en su momento consciente de la visión kantiana de su propuesta (2000), su política de una $\mathrm{u}$ otra forma aspiraba a la universalidad, en los términos en que: "el principio de nuestra acción se convierta en una ley universal" (Blackburn, 2006, p. 114) y que "toda ética formalista ha de poder senalar un principio que básicamente permita llegar a un acuerdo racionalmente motivado" (Habermas, 1998, p. 68); se trataba de generar una política tan asertiva y universal como lo es el mismo sentimiento de la felicidad:

Esta es, a mi juicio, la clave del Ethos ilustrado: La urgencia de introducir en los saberes que rigen la conducta la claridad que ya brilla en los de la naturaleza, para lograr el auténtico progreso, que es la transformación del obrar con vistas a la perfección o a la felicidad. (Cortina, 2000, p. 101).

Se asume entonces que un ciudadano, dígase: violento, quemado por la pólvora o atropellado en las calles, no es feliz o que a este ciudadano le es más difícil ser feliz dado que -en términos de la cita anterior y desde el ethos de la Ilustración-, le es más difícil llegar a un estado de felicidad. Dicho esto en otras palabras, si el ciudadano respeta la vida y la salud, la probabilidad de ser feliz, es más amplia que si no se respetan ambos aspectos. Ahondando ahora en lo que se refiere a lo didáctico o educativo, durante la administración de Mockus tomó relevancia el término pedagogías ciudadanas (Burbano, 2009), término que se encuentra muy relacionado con las denominadas reglas de lugar, entendidas estas como el proceso normativo mediante el cual es posible que "las personas se autorregulen, contribuyendo a crear y mantener prácticas culturales deseables que puedan ser transmitidas en el transcurso del tiempo entre generaciones" (Burbano, 2009, p. 42). Por consiguiente, en términos de gobernabilidad se pretendió que los ciudadanos se educasen entre todos, a través de la desaprobación social hacia las conductas que eran al mismo tiempo condenables moralmente, como también ilegales para todos ${ }^{6}$; lo anterior posibilitaba al mismo tiempo una responsabilidad para todos los comunes de la sociedad. En otros términos, no debía existir "ningún derecho sin responsabilidad" (Giddens citado por Laval y Dardot, 2015, p. 477).

Como consecuencia de lo anterior, "la represión policial se volvía la última medida de una secuencia pedagógicamente ordenada y se ampliaba el efecto pedagógico gracias a la claridad de la lectura de la situación y al respaldo social dado a la sanción" (Mockus, 2000). Argumentando un poco lo anterior, puede decirse que existía (y existe aún) un amplio grupo de poblaciones dentro de la ciudad, todas ellas con códigos morales de distinta naturaleza y procedencia; no obstante, la Alcaldía Mayor de Bogotá se encargó -y a nivel ético-político-, de generar una ética de ciudad por encima de la multiplicidad de valores morales, presentes tanto

6 Aunque esta precisión debería inferirse como un axioma, tal inferencia no resulta ser del todo evidente, dado que existe, según Mockus, un divorcio entre los conceptos: ley moral y cultura (Mockus, 2000), como se expuso anteriormente. 
en los colectivos humanos (Cortina y Martínez, 2001) o de la pretensión de generar buenas costumbres locales (Bauman, 2013), al interior de la amplia variedad de anfibios culturales (Mockus, 1994; Fals, 2002) que habitaban y aún habitan la ciudad. Existen múltiples análisis para tener en cuenta en el asunto de la gobernabilidad desarrollada por Mockus, no obstante, algo comprensible es precisamente la necesidad de generar nuevos ciudadanos o una nueva ciudadanía, todo ello a través de una nueva forma de verse y comportarse.

La tarea de los educadores queda así clarificada: si queremos modelar personas capaces de respetar las diferencias, tenemos que proporcionar modelos y ofrecer lecciones que fomenten esta actitud comprensiva. (Gardner, 2016, p. 156).

La perspectiva ética... nos exige superar nuestro punto de vista personal y adoptar el punto de vista de un observador imparcial" (Singer citado por Gardner, 2016, p. 203).

La superación del ser, si bien puede provenir de múltiples factores, es un acto educativo con intención de obtener mejores resultados. Si bien la pedagogía como disciplina de conocimiento -y en una comprensión básica-, vendría a significar como: "la reflexión sobre el acto de educar" (Zambrano, 2015, p. 53), también se ha dicho que la pedagogía es un campo de acción política en la escuela (Díaz, 2005; Unda, 2009). No obstante, esta disciplina de conocimiento se puede sintetizar al decir que "el objeto de la pedagogía es la práctica social de la educación" [indicándose que se trata de una] "ciencia de la práctica" (Garrido, 2013, p. 118-126). Como parte del discurso de la pedagogía, hallamos la idea de didáctica como un campo del saber que en su acepción clásica pretende dar cuenta de los procesos de enseñanza y aprendizaje; dicha concepción básica se resignifica al afirmar que:

Nuevas concepciones de didáctica están emergiendo de la investigación sobre la enseñanza como una práctica social viva, en los contextos sociales e institucionales en donde ocurren, es decir, a través de la sistematización y las explicaciones de la práctica pedagógica. (Garrido, 2013, p. 118).

Entendiéndose también como didáctica:

Una teoría práctica de la enseñanza ( $y$ que) tiene como objeto de estudio la enseñanza, tomada en su realidad práctica y social (la cual está encargada de) en el sentido de transformar las persistentes condiciones de enseñanza y aprendizaje selectivas y excluyentes, de gestar prácticas pedagógicas capaces de crear... condiciones de emancipación y desarrollo social, cultural y humano. (Garrido, 2013).

Ahora bien, si "el objeto de investigación de la didáctica es la enseñanza" (Garrido, 2013, p. 130), se indicaría que las prácticas desarrolladas en el Gobierno de Mockus eran prácticas educativas y entonces se desarrollaría una reflexión sobre la práctica. El término pedagogías ciudadanas es una categoría que se ha venido legitimando con el paso del tiempo ${ }^{7}$, entre otras cosas porque

7 Resulta difícil comprender que: "a pesar de los indudables aciertos y logros de la estrategia de pedagogía ciudadana en los dos Gobiernos de Mockus... esta fue abandonada en la administración de Luis Garzón... de manera infortunada". (Sáenz, 2009, p. 27). 
es un nombre bien adjudicado; no obstante, se habla en este texto de una didáctica, ya que "la didáctica hace visible la insoportable fabricación del espíritu humano y esto porque ella se limita a los procesos de enseñanza en función de los aprendizajes" (Zambrano, 2015, p. 59). Las ideas de civismo fueron dejadas de lado en administraciones posteriores, quizás debido a la falta de principios o criterios de necesidad común al interior de las administraciones políticas. De lo anterior, emerge la necesidad de generar continuidad sobre lo hecho, tomando como base el establecimiento de principios de necesidad común:

¿Qué es un principio? Un principio es lo que aparece primero y funda todo el resto. Un principio no es un 'comienzo' que tiene la virtud de "borrarse ante lo que le sigue", o un simple 'punto de partida' que uno dejaría atrás para no volver a él, sino un verdadero comienzo, un 'comienzo que sigue comenzando', esto es, un comienzo que rige y domina todo lo que sigue. (Laval y Dardot, 2013, p. 99).

En términos de la discusión sobre los principios vale la apreciación de Howard Gardner: "una mala persona no llega nunca a ser un buen profesional"8 (Gardner, entrevistado por Aldana, 2016). Si bien las universidades deben cumplir la función de asesorar al Estado, se requiere sopesar dos aspectos cruciales en el desarrollo de un buen profesional: a) el saber profesional, que se dota de una habilidad disciplinar $\mathrm{y}, \mathrm{b}$ ) la persona,

8 El neuro pedagogo se ve ante la necesidad de categorizar a las personas bajo las polaridades: bueno-malo, y aunque dicha distinción pueda parecer ficticia, en determinado momento es necesaria para establecer un juicio entre los profesionales éticos y los inescrupulosos. que crea una relación también de calidad en su entorno de vida. Para Gardner estos dos aspectos no se encuentran separados. Según el pedagogo, las personas carentes de escrúpulos adquieren solo una "pericia técnica, pero no son excelentes" (Gardner, entrevistado por Aldana, 2016). Gardner, conocedor profundo de las capacidades cognitivas del ser humano, determina que los mejores profesionales suelen ser personas siempre ECE: excelentes, comprometidos y éticos, cualidades que son contenidas en el sentido de la responsabilidad, en tanto que "una postura verdaderamente ética es el sentido de la responsabilidad" (Gardner, 2011, pp. 105-106), dado que dicha responsabilidad "apunta últimamente a conseguir un auto-gobierno del propio individuo" (Laval y Dardot, 2013, p. 3).

En consecuencia y teniendo en cuenta lo anterior, es necesario indicar que indicar que el docente -si bien está directamente relacionada con la formación del ser humano-, no es la única persona sobre quien recae la necesidad de formar; la educación como principio básico de las sociedades modernas ha de ser posible entre pares o entre comunes, lo cual es factible a través de la creación de sentidos entre ciudadanos, relación que se logra establecer sobre las significaciones y las prácticas de lo común:

El ser humano no solo es el único animal "lógico", sino también el único animal "ilógico". Es el único animal que utiliza significaciones -ideas, conceptos, analogías, metáforas, modelos, teorías y explicaciones- para dar sentido a las cosas, para comprenderlas, preverlas y dominarlas. (Paul, citado por Blackburn, 2006, p. 23). 
La pedagogía ciudadana (Burbano, 2009), vista en re-play, desarrolló un valioso grupo de significaciones sobre lo común. En las administraciones de Mockus se apeló continuamente a los valores éticos de la sociedad; así -más allá de los discursos de los claustros universitarios-, la ética pasó de ser un campo de estudio de la filosofía, a una práctica directa en las calles y con un sentido social común. La didáctica de una ética ciudadana se convirtió en una práctica social viva, dando lugar $-y$ de manera quizás muy paradójica-, a una enseñabilidad desarrollada por la ciudadanía, o por el común de ciudadanos. Mockus logró desarrollar desde la Alcaldía de Bogotá, en buena medida, una didáctica social en función de la transformación del sentido ético de ciudad de los capitalinos, fortaleciendo una cultura cívica y un respeto por la vida. Todo lo anteriormente dicho es un campo de reflexión para la didáctica.

\section{Conclusiones}

El "experimento" realizado en la ciudad de Bogotá hace ya más de 20 años, no ha visto continuidad a pesar de su imperante necesidad en la sociedad, situación que no habla bien de la política colombiana. El modelo de Mockus -salvo muy raras excepciones-, no pretende modificar la normatividad jurídica o constitucional desarrollada en la Constitución colombiana; su propuesta está dirigida a mejorar a los ciudadanos, necesidad que tiene cada vez más importancia en un país que adolece de procesos administrativos libres de corrupción. A lo anterior, se suma otro factor y es que Colombia -entendida como la suma de sus ciudadanos y no como un solo territorio- es una nación a la cual le hace falta amarse a sí misma; ello requeriría un trabajo en varios frentes, y de acciones básicas, dirigidas al perdón (Mockus, 2002b) y la reconciliación de sus ciudadanos; para ello, el ideal mockusiano de vencer la zanja entre ley moral y cultura, implica que es posible: "restablecer la relación, las identidades y el consenso sobre la validez de la norma trasgredida" (Mockus, 2002b, p. 54) y también la norma que se acata $\mathrm{u}$ obedece.

En el país urge la resignificación de una ética que resulte ser de aplicación directa y pragmática sobre los eventos y actos sociales, una ética que sea capaz de dialogar con la diferencia y que permita establecer concreciones sobre aquello que favorece el modo de vida de la mayoría, en un sentido comprensivo sobre la responsabilidad individual y social. En concordancia con lo anterior, no resulta posible pensar en una sociedad pacífica, al interior de una cultura anticívica, pues donde no existe la base del respeto no es factible una sociedad pacífica". Acudiendo a casos no del todo hipotéticos, aunque la ley puede ser violada, si la cultura es consciente de que determinado acto no está moral o éticamente correcto, dicha cultura no necesita supervisión gubernamental, pues ella misma se encarga de corregir prácticas que no son en sí mismas necesidades primordiales, dígase culturales.

Los aportes de Mockus en el campo de la gobernabilidad son de gran valía - ya no para la capital de Colombia sino para Colombia misma - ; dicha cuestión resulta ser tan importante como la misma producción

9 En este punto es necesario detenerse, pues para lograr una cultura más pacífica no solo es necesaria la base del respeto, sino también la equidad y la justicia social. No obstante, abordar dicho tema excede las posibilidades del presente escrito, dado que amplía mucho más la discusión aquí presente. 
teórica que se pueda desarrollar sobre el campo de la ética, al interior de los claustros universitarios. En lo que a gobernabilidad se refiere, Sáenz (2009) afirma que "los Gobiernos de Mockus buscaron pedagogizar la intimidad de los individuos por medio de la formación de sentimientos morales" (p. 31); la aplicabilidad de ello es hoy en día un ejemplo histórico, que amerita además de réplicas, refinamientos y mejoras. Una de las valías de este modelo de gobernabilidad estuvo en que -en muchos casos-, fue la población misma la que sirvió de veeduría para el cumplimiento de la ley, de tal suerte que fue el bien común el que logró ajustarse a la actividad gubernamental. La ley no solo puede operar desde el órgano administrativo hacia la ciudadanía, sino que también puede llegar a establecer coobligaciones e intercambios recíprocos entre individuos en la ciudad. Laval y Dardot (2015) indican que "la democracia es el reino de la ley para todos, es el gobierno mediante la ley común hecha por los hombres" (p. 137), ello desde luego le da la razón al exalcalde, en cada una de las prácticas didáctico-pedagógicas desarrolladas durante su administración.

Aunque los detractores de las propuestas mockusianas han calificado sus administraciones como "autoritarias", no obstante sus Gobiernos sí fueron dialógicos con sectores excluidos y "buscaron pedagogizar la intimidad de los individuos por medio de la formación de sentimientos morales" (Sáenz, 2009, p. 31); preocupación no vehemente en la inmensa mayoría de administraciones públicas del país. Si bien se podría decir que actividades como las generadas durante las administraciones de Mockus, permitieron una interacción ciudadana en donde se permitía "jugar activamente con el espacio de libertad dejando a los individuos para que acaben sometiéndose por sí mismos a ciertas normas" (Laval y Dardot, 2013, p. 5), es necesario también explicitar que, si una ley es culturalmente validada resulta imperativo cumplirla. Por lo tanto, una didáctica de la ética es necesaria para la gobernabilidad de la nación, y esta debe discutirse y llevarse a la práctica, en razón de lo común.

Antanas Mockus hizo un gran aporte a la gobernabilidad en el país; sus Gobiernos se encargaron de ser, hacer y enseñar. La política colombiana trascendió el Estado controlador y castigador y pasó a ser un Estado primeramente educador. En una mirada retrospectiva al programa de gobierno de Mockus, se observa que hubo un despliegue de la didáctica destinada al fortalecimiento de la ética ciudadana, una didáctica externa a la escuela, pero comprometida con la formación de nuevos ciudadanos. En este orden de ideas, la propuesta no pretendió nuevas leyes para controlar a los ciudadanos, sino que aspiró a formar nuevos ciudadanos con capacidad de autorregularse a sí mismos a través de una reflexión sobre el beneficio común. Todo lo anterior, visto como una propuesta pedagógica y didáctica sobre la ética, se constituye como el gran aporte de Mockus al ejercicio de la gobernabilidad en el país.

\section{Referencias}

Ackerley, M. (2008). Una Ética en Gottfried Wilhelm Leibniz. Eikasia, Revista de filosofía, 3(16), 239-246.

Aldana, R. (2016). Una mala persona no llega nunca a ser buen profesional. Recuperado de https://lamenteesmaravillosa. 
com/una-mala-persona-no-llega-nunca-buen-profesional/

Bauman, Z. (2013). Ética osmoderna. México D. F., México: Siglo Veintiuno Editores.

Beltrán, D. (2003). "Sobre las razones de creación de la Defensoría del Espacio Público y sus resultados" en Bogotá y lo público: Colección Construcción de lo público, (1), 102-112. Bogotá D. C., Colombia: Edición Universidad de los Andes.

Blackburn, P. (2006). La ética: fundamentos y problemáticas contemporáneas. México D. F., México: Renouveau pédagogique.

Burbano, A. (2009). La convivencia ciudadana: su análisis a partir del "aprendizaje por reglas". Revista Colombiana de Educación, 57. DOI: https://doi. org/10.17227/01203916.7587

Camilloni, A. (2007). El saber didáctico. Madrid, España: Editorial Paidós.

Cortina, A. (2000). Ética mínima. Introducción a la filosofía práctica. Madrid, España: Editorial Tecnos S. A.

Cortina, A. (2004). Por una ética del consumo. Madrid, España: Santillana.

Cortina, A. y Martínez, E. (2001). Ética. Madrid, España: Akal.

Cruz, E. (2010). La Constitución Política de 1991 y la apertura económica. Revista de la Facultad de Ciencias Económicas. 18(1), 269-280. DOI: https://doi.org/10.18359/ rfce. 2292

Díaz, A. (2005). El docente y los programas escolares. Lo institucional y lo didáctico. Barcelona, España: Editorial Pomares.

Díaz, R. (5 de enero del 2009). Antanas y los mimos. Pedestre Blog. Pp. 1. Recuperado de https://ciudadpedestre. wordpress.com/2009/01/05/antanas-y-los-mimos/Fals, O. (2002). Historia doble de la costa. Bogotá D. C., Colombia: El Áncora Editores.
Gardner, H. (2011). Verdad, belleza y bondad reformuladas. la enseñanza de las virtudes en el siglo XXI. Barcelona, España: Paidós.

Gardner, H. (2016). Las cinco mentes del futuro. Bogotá D. C., Colombia: Paidós.

Garrido, S. (2013). Hacia una resignificación de la didáctica, ciencia de la educación. Pedagogía y didáctica, 39, 117-139. DOI: https://doi.org/10.17227/01212494.39p ys117.139

Gómez, L. y Peñaloza, G. (2014). Didáctica y comunicación: Aportes de Habermas a la educación. Praxis y saber, 5(9), 13-29. DOI: https://doi.org/10.19053 /22160159.2991

Habermas, J. (1998). Escritos sobre moralidad y eticidad. Barcelona, España: Paidós.

Laval, C. y Dardot, P. (2013). La nueva razón del mundo. Ensayo sobre la sociedad neoliberal. Barcelona, España: Gedisa.

Laval, C. y Dardot, P. (2015). Común. Ensayo sobre la revolución en el siglo XXI. Barcelona, España: Gedisa.

López de Lizaga, J. L. (2008). La ética del discurso y el concepto kantiano de deberes hacia uno mismo. Estudios de Filosofía, (38), 103-120.

Mockus, A. (1994). Anfibios culturales, moral y productividad. Revista Colombia de Psicología.

Mockus, A. (2000). Armonizar ley, moral y cultura. Cultura ciudadana, prioridad de gobierno con resultados en prevención y control de violencia en Bogotá 1995-1997. Bogotá D. C., Colombia: Mimeo.

Mockus, A. (2001). Cultura ciudadana, programa contra la violencia. Washington $\mathrm{D}$. C.: Banco Interamericano de Desarrollo. Mockus, A. (2002a). Convivencia como armonización. Ley, moral y cultura. Perspectivas, (23). 
Mockus, A. (2002b). ¿Para qué el perdón? Theológica Xaveriana.

Mockus, A. (2003). Cultura ciudadana y comunicación. Bogotá D. C., Colombia: La Tadeo, 106.

Montoya, C. y Cendrós, P. (2007). Elementos de la ética kantiana aplicables a las organizaciones educativas. Laurus, 13(25).

Naranjo, G. (2002). Ciudades y desplazamiento forzado en Colombia. El "reasentamiento de hecho" y el derecho al restablecimiento en contextos conflictivos de urbanización". En Marta Nubia Bello (ed.), Desplazamiento forzado: dinámicas de guerra, exclusión y desarraigo. Bogotá D. C., Colombia: Acnur - Universidad Nacional de Colombia.

Pardo, M. (2007). Territorialidades cívicas, espacio público y cultura urbana En Bogotá, Colombia. Leiden, Holanda: Universiteit Leiden.

Parra, S. (18 de mayo del 2013). La ley zanahoria y otras cosas que cambiaron Bogotá (y el mundo) gracias a un hombre con una pistola de plástico. Diario Del Viajero. P. 1. Recuperado de https:// www.diariodelviajero.com/america/laley-zanahoria-y-otras-cosas-que-cambiaron-bogota-y-el-mundo-gracias-aun-hombre-con-una-pistola-de-plastico

Redacción El Espectador. (29 de agosto del 2018). Quién ganó y quién perdió con la consulta anticorrupción. El Espectador. Recuperado de https://www.elespectador.com/noticias/politica/quien-ganoy-quien-perdio- con-la-consulta-anticorrupcion-articulo -808457

Redacción El Tiempo. (11 de diciembre de 1995). Quedó prohibida la pólvora en Bogotá. El Tiempo. P. 1. Recuperado de http://www.eltiempo.com/archivo/documento/MAM-479820
Redacción El Tiempo. (23 de julio del 2018). Lo que dice el Código de Ética sobre la bajada de pantalones de Mockus. El Tiempo. Recuperado de http:// www.eltiempo.com/politica/congreso/pueden-sancionar-a-antanas-mockus-por-bajarse-los-pantalones-246638

Sáenz, J. (2009). La pedagogía ciudadana en Bogotá: ¿un proyecto autoritario, o el mínimo común necesario para la construcción de una democracia radical? Educación y ciudad.

Spinoza, B. (2005). Ética demostrada según el orden geométrico. Madrid, España:Alianza Editorial.

Tibaná, D. (4 de marzo de 1996). Antanas Mockus prueba vacuna contra la rabia. El Tiempo. P. 1. Recuperado de http://www.eltiempo.com/archivo/ documento/MAM-348471

Unda Bernal, M. del P., Guardiola Ibarra, A., Constán Medero, S., Berrío Morelo, O. B. M. y Martínez Camacho, M. (2009). Pedagogía, interculturalidad y formación de maestros: Escuela Normal Superior Indígena de Uribia (Guajira). Pedagogía y Saberes, (30), 113-120. DOI: https://doi.org/10.17227/01212494 .30pys 113.120

Zambrano, A. (2015). Pedagogía y didáctica: esbozo de las diferencias, tensiones y relaciones de dos campos. Praxis y Saber, 7(13), 45-61. DOI: https://doi. org/10.19053/22160159.4159 